\title{
КОНЦЕПЦИЯ МАРКЕТИНГОВОЙ ДЕЯТЕЛЬНОСТИ ОРГАНИЗАЦИЙ СФЕРЫ УСЛУГ ФИЗИЧЕСКОЙ КУЛЬТУРЫ И СПОРТА
}

\author{
Илья Ерёмин, Людмила Толстая, Елена Ерёмина \\ Ставропольский государственный медицинский университет, Россия
}

\begin{abstract}
АННОТАЦИЯ
В статье рассматриваются понятие спортивного маркетинга и особенности системы маркетинговой политики организаций, действующих на рынке услуг в сфере физической культуры и спорта. Определяется социальный характер спортивного маркетинга, выражающийся в удовлетворении потребностей населения в отношении занятий физической культурой и спортом; сегментировании рынка не только по географическим и социально-демографическим признакам, но и образу жизни, социально-культурной ориентации.
\end{abstract}

Ключевые слова: спортивный маркетинг, рынок услуг физической культуры и спорта.

\section{ВВЕДЕНИЕ}

С каждым годом физическая активность и спорт всё в большей степени проникают в повседневную жизнь людей: повсеместно возрастает количество спортивных клубов и организаций, увеличивается число людей, приобщающихся к спорту, растет количество и качество спортивных средств массовой информации.

Оценивая объём российского рынка спорттоваров, эксперты называют цифры от 0,6 до 4 \$ млрд., ежегодный прирост при этом составляет 15-20\%. По мнению международных экспертов, российский рынок спортивных товаров и услуг относится к числу наиболее перспективных.

Несмотря на отсутствие точных данных, можно сказать, что данный сегмент потребительского рынка находится в настоящий момент в процессе активного роста. Этому способствуют как благоприятные макроэкономические факторы, так и изменения потребительских предпочтений. В частности, увеличивается доля населения, которое активно занимается спортом.

Актуальность. Складывающиеся на современных спортивных рынках тенденции вместе с массовым спросом обеспечивают производителям спортивной продукции и услуг огромные прибыли, за обладание которыми идет жесткая конкурентная борьба.

Выиграть конкурентную борьбу в условиях постоянного противоборства с соперничающими фирмами - производителями и спортивными организациями можно лишь прибегнув к маркетингу.

Научная новизна. Определение критериев концепции маркетинговой деятельности, обуславливающих успех предприятий и организаций, оказывающих и продающих услуги физической культуры и спорта.

Практическая новизна. Сформулированные в работе научные положения могут быть использованы в маркетинговой политике организаций, работающих в спортивной 
сфере. Взаимодействие потребителей и фирм, стремящихся к качественному удовлетворению потребностей, будет способствовать повышению качества жизни и обеспечению условий для ведения здорового образа жизни.

Цель. Определение особенностей концепции маркетинговой деятельности организаций сферы услуг физической культуры и спорта.

\section{Задачи:}

1. На основе разных точек зрения дать определение понятию «спортивный маркетинг».

2. Раскрыть особенности маркетинговой деятельности организаций, работающих в сфере физической культуры и спорта.

\section{МЕТОДОЛОГИЯ И МЕТОДЫ ИССЛЕДОВАНИЯ}

В работе использованы в совокупности общенаучные (анализ, синтез, сравнение, обобщение) и конкретно-научные (теоретический) методы исследования.

\section{РЕЗУЛЬТАТЫ ИССЛЕДОВАНИЯ И ИХ ОБСУЖДЕНИЕ}

Маркетинг представляет собой философию бизнеса, инструментарий предпринимательства, стратегию и тактику участников рыночных отношений. Именно глубокие знания маркетинга, способность умело применять современные инструменты воздействия на ситуацию, складывающуюся на рынке, предопределяют коммерческий успех спортивного предпринимателя.

Эванс и Берман (Эванс, Берман, 2002) в своей работе определяют маркетинг следующим образом: «Маркетинг - это предвидение, управление и удовлетворение спроса на товары, услуги, организации, людей, территории и идеи посредством обмена».

На наш взгляд, отличительная особенность маркетинга как стиля, метода, концепции управления бизнесом заключается в постоянной заботе организации об удовлетворении потребностей клиентов, тем самым, достигая своих целей.

Спортивный маркетинг представляет собой составную часть общего маркетинга, имеющего свои специфические черты и особенности. В частности, в поле зрения спортивного маркетинга попадают субъекты: личность (семья); организации, продающие услуги; предприятия и организации, приобретающие услуги для использования в своей деятельности; государство в лице органов управления физической культурой и спортом; посреднические организации, содействующие продвижению спортивных товаров и услуг, а также такие особые объекты и отношения, как болельщики, спонсоры, купля продажа спортсменов, массовый спорт, спортивный бизнес, здоровый образ жизни и многое другое.

Бич и Чедвик (Биг, Чедвик, 2010) дают следующее определение: «Спортивный маркетинг - это непрерывный поиск возможностей комплексного решения как непосредственных, так и косвенных задач потребителей спорта, компаний, работающих в спортивной сфере, и других физических лиц и организаций, связанных со спортом, в условиях изменчивой и непредсказуемой среды». 
Организациям физкультурно-спортивной направленности необходимо учитывать ряд особенностей, которыми обладает рынок услуг физической культуры и спорта:

- «продукты» такого производства (в подавляющем большинстве случае это услуги) носят не столько вещественный, сколько социально-культурных характер, поскольку связаны с феноменами культуры и духовной жизни общества. Потребление таких услуг способствует удовлетворению духовных, интеллектуальных потребностей индивида, содействует поддержанию его нормальной жизнедеятельности;

- типичные потребители услуг в сфере физической культуры и спорта - дети, подростки, учащаяся молодежь (Степанова, 2005).

Проблемное содержание маркетинговой деятельности предприятий, организаций и учреждений сферы услуг физической культуры и спорта связано, с одной стороны, с решением вопросов маркетинга в отношении товарной, ценовой, сбытовой, коммуникационной и кадровой политики, а с другой стороны, обладает рядом особенностей, обусловленных спецификой как самой сферы физической культуры и спорта, так и потребителей услуг этой сферы.

В маркетинге спортивных услуг особенно весома роль государства. Это связано с тем, что успех реализации маркетингового потенциала в сфере физической культуры и спорта во многом определяется практическими мерами содействия ему со стороны государственных органов управления всех уровней.

Государство призвано выполнять ряд специфических маркетинговых функций: проектирование и строительство рыночных отношений, организация и обеспечение маркетинговой деятельности в сфере услуг физической культуры и спорта.

Успех деятельности предприятий и организаций, оказывающих и продающих услуги физической культуры и спорта, во многом зависит от маркетинговых успехов персонала, призванного осуществлять обширный спектр соответствующих функций - от изучения рынка и разработки стратегии маркетинга до сопровождения услуги в процессе еe потребления.

Маркетинг в физкультурно-спортивной деятельности носит не столько коммерческий, сколько социальный характер, так как физическая культура и спорт относится к социальнокультурной сфере. Это определяется следующим:

- маркетинг изначально направлен на выявление и определение способов наиболее полного удовлетворения потребностей (запросов, предпочтений) населения в отношении занятий физической культурой и спортом;

- спортивный маркетинг почти исключительно опирается на социологические методы сбора и анализа информации;

- сегментация рынка осуществляется не просто по географическим и социальнодемографическим признакам, а производится по более тонким основаниям, таким, как образ жизни, социально-культурные ориентации и поведение. Основополагающее воздействие оказывают мотивы потребления на основе получения 
выгод, в данном случае, весьма привлекательных преимуществ от здорового образа жизни и специфической формы досуга. Это преимущество целесообразно принять в качестве основного системообразующего признака сегментирования на спортивном рынке (Дубровин, Харчук, 2000);

- маркетинговое воздействие на потребителей, социальную среду - это по сути воздействие социально-психологическое.

Также маркетинг в сфере физической культуры и спорта должен учитывать законодательство, интересы властей, общественных движений, учитывать специфику средств массовой информации и коммуникации, то есть действовать в широком социальном контексте.

\section{ВЫВОДЫ И ПЕРСПЕКТИВЫ}

1. Социальный характер спортивного маркетинга представляет собой особую разновидность социальной работы с населением, технологию социальнокультурных нововведений, маркетинг идей, видов спорта, соревнований, территорий и мест, направленных на воспроизводство национального человеческого потенциала. Помимо этого, маркетинг - это теория и практика управленческой деятельности, философия субъектов рынка отрасли «физическая культура и спорт».

2. Главная и основная задача маркетинга в сфере физической культуры и спорта в настоящее время - не покушаясь на суверенитет потребителя, сформировать его покупательское поведение таким образом, чтобы он стал постоянным, пожизненным приверженцем физкультурно-спортивных услуг и при этом предпочел услуги того производителя, который наиболее эффективно использует маркетинг и его возможности.

\section{ЛИТЕРАТУРА}

1. Биг, Д., Чедвик, С. (2010). Маркетинг спорта. Пер. с англ. Москва: Альпина Паблишерз. C. 37 .

2. Дубровин, И. А., Харчук, А. Г. (2000). Спортивный маркетинг. Российское предпринимательство, 3 (3), 27-35.

3. Степанова, О. Н. (2005). Маркетинг в сфере физической культуры и спорта. Москва: Советский спорт. С. 9-10.

4. Эванс, Дж. Р., Берман, Б. (2002). Маркетинг. Пер. с англ. Москва: Сирин. 


\title{
THE CONCEPT OF MARKETING ACTIVITY OF THE ORGANIZATIONS IN THE SPHERE OF SERVICES OF PHYSICAL EDUCATION AND SPORTS
}

\author{
Ilya Eremin, Lyudmila Tolstaya, Elena Eremina
}

Stavropol State Medical University, Russia

\begin{abstract}
Every year physical activity and sport increasingly penetrate into people's daily lives: everywhere the number of sports clubs and organizations increases, as well as the number of people attracted to sport.

Assessing the volume of the Russian market of sports goods, experts give the numbers from 0.6 to 4 \$ billion, the annual growth rate of 15-20\%. According to international experts, the Russian market of the sports goods and services is among the most promising.

Despite the lack of precise data, we can say that this segment of the consumer market is currently in the process of active growth. This is facilitated by favourable macroeconomic factors, and changes in consumer preferences.

The relevance of the research is determined by folding in modern sports markets trends, which together with a massive demand ensure that manufacturers of sports goods and services have huge profits, the possession of which conditions stiff competition. Winning the competitive struggle in the conditions of constant confrontation with rival manufacturers and sports organizations can only be resorted to marketing.

Scientific innovation. Definition of criteria for the concept of marketing activities that lead to success of enterprises and organizations providing and selling services for physical training and sports.

Practical innovation. Formulated scientific principles in the work can be used in the marketing policy of the organizations working in the sphere of sports. Interaction of consumers and firms seek for quality, which will improve the quality of life and ensure the conditions for a healthy lifestyle.
\end{abstract}

Keywords: sports marketing, the market for physical education and sports. 